\title{
Superleader Behaviors And Self-Managed Work Teams: Perceptions Of Supervisory Behaviors, Satisfaction With Growth, And Team Functions
}

David F. Elloy, (Email: elloy@jepson.gonzaga.edu), Gonzaga University

\begin{abstract}
This study examined the effects of SuperLeader behaviors on self-managed work groups in a nonunion paper mill which had self-managed work teams in place since it began its operation. Based on a sample of 141 employees, the results indicated groups that were led by a supervisor who exhibited the characteristics of a SuperLeader (as described by Manz and Sims, 1990) exhibited higher levels of fairness, trust, growth and overall support. These groups also reported higher levels of team communication, team effectiveness, team training and recognition.
\end{abstract}

\section{INTRODUCTION}

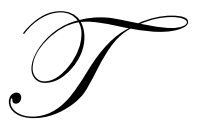

here is ancient Chinese saying by Lao Tzu that says that "the best of all leaders is the one, who helps people so that, eventually, they don't need him.” This statement seems to idealistically capture what seems to be the future structure of organizations. The changing environment driven by market forces have made it necessary for them to examine the way they design jobs to meet these challenges and new approaches are required to deal with the increasing interdependence, complexity and environmental uncertainty.

One such approach is the use of self-managed teams. Management typically introduces self-managed teams in the hope of increasing productivity, improving product quality, and reducing overhead. It provides an opportunity for the employees to run the day to day operations of the organization with no unnecessary influence from top management. The use of self-managed work teams has grown considerably in the US and it has become an important management innovation over the past decades with up to half of all employees soon to be working in a team environment (Manz and Sims, 1993; Stewart and Manz, 1995). Studies have indicated that work teams have been central to the effectiveness of organizations (Dunphy and Bryant, 1996), and based on a 1993 survey (Lawler et al, 1994) found that 68 per cent of Fortune 1000 companies use self-managed work groups and 28 percent use employee participation groups of some sort.

The concept of self-managed work teams was originally developed by Emery and Trist, 1969. Several characteristics typically distinguish self-managed work from other teams. For example, it is not a team brought together for a special purpose, such as a product-launch team, a quality action team, or a quality circle, instead, selfmanaged work teams are ongoing day to day continuous teams, where work is usually designed in a way where team has ownership of a product or service. Self-managing work teams are relatively small groups that take complete responsibility for making a product or delivering a service, performing a variety of tasks and utilizing a number of skills which the group as a whole possess (Wall, Jackson and Clegg, 1986). Providing this type of ownership usually requires broader job categories and the sharing of work assignments, rather than mastering one job and remaining at the job. Team members operate without a visible manager and assume many primary responsibilities of management. Where this management system exists, control and accountability are pushed down to the lower levels of the organization. It is hypothesized that self-managed work teams are effective, contribute to employee quality of work life (Cohen and Ledford, 1994). They also produce outcomes such as increased employee satisfaction, the opportunity 
for increased socialization in the workplace, increased autonomy, opportunity to learn new skills, and other aspects such as reduced absenteeism, turnover and increased performance and motivation (Cohen and Ledford, 1994; Pearson, 1992; Stewart and Manz, 1995; Wall, Kemp, Jackson and Clegg, 1986). Overall, the research on self-managing work teams indicates clear benefits both in performance and in attitudes (Glassop, 2002; Guzzo and Dickson, 1996; Cohen and Bailey, 1997).

In research studies there has been considerable focus on the effects of either individual autonomy or the autonomy of the team on performance and other outcome measures, but little attention has been given to the efficacy of the leader on team outcomes. Manz and Sims (1986) for example describe leadership in a self-managing work team environment as something of a paradox. According to their view the role of the supervisor is to help employees generate self-control. The supervisor encourages self-managing work team members to develop their performance standards, conduct self-evaluations and self regulate their own behavior. Because work team members in the process of producing a product or delivering a service, learn how to perform those behaviors, self-leadership is therefore expected to have a direct impact on performance effectiveness.

Underlying this whole process of self-management is self-regulation (Manz and Sims, 1987). Consequently, leadership when applied to self-managing work teams is reflected in the idea of "a person who leads others to lead themselves" (Manz and Sims, 1987, Manz and Sims 2001). Termed the 'SuperlLeader' Manz and Sims (1990) identifies six behaviors that should be performed in order to help a self-managing work team to manage itself.

The six leadership behaviors are: (1) Behavior that encourages self-reinforcement by team members. Through the reinforcement of high levels of group performance, the Superleader encourages the group to recognize and appreciate actions that lead to high performance; (2) Encouraging self-evaluation so that team members gather the relevant information to monitor and evaluate their performance; (3) Team members are encouraged to be self-critical of their own performance; (4) By promoting a culture based on group outcomes the SuperLeader helps assist team members to engage in behavior of self-goal setting; (5) Encouraging self-expectation among work team members so that the team has high expectations for group performance; (6) Encouraging the behaviors of task rehearsal so that the team practices a work activity before performing it.

There have been a few studies done to validate Manz and Sims' (1987) theory. Elloy (1997) for example in a study of self-managed work groups in a government operated railway service found, that supervisors who were seen as fair, trusting, encouraging innovative behaviors, and who positively reinforced group members contributed to the development of self-management behaviors of rehearsal, self-goal setting, self criticism, self-reinforcement, selfexpectation and self-observation. In addition, the study found that fostering communication within the group, and allowing group members to make work related decisions also enhanced the movement towards self-management. In a further examination of the data, Elloy and Randolph (1997) found that groups, that were lead by a supervisor who exhibited the characteristics of a SuperLeader, had higher levels of satisfaction, commitment, organization selfesteem, and communication effectiveness, but also higher levels of role conflict and role ambiguity. Similar results were found by Elloy (2005) in a more recent study of employees working in a paper mill.

Based upon the characteristics of self-managed work teams, and the organizational culture that supports this job design, it is reasonable to assume that, task identity will be enhanced through a collective responsibility for completing a whole piece of work (Hackman and Oldham, 1975; Hackman 1987). SuperLeader behaviors would also encourage the group to self-regulate its activities by allowing team members to control technical variances within the boundaries of the group (Cummings, 1978). This means that individuals would need the freedom to perform their jobs as they see fit and in ways that they find most rewarding. From this, one can make the case that team members will experience higher levels of trust, encouragement of innovative behaviors, and growth. The following hypothesis is therefore proposed:

Hypothesis 1: Groups with high SuperLeader behaviors will have higher perceived levels of trust, innovation, fairness, growth, and recognition. 
Another characteristic of self-managed work teams is the autonomy to make decisions with respect to work related issues. Team members are encouraged to deal with task and environmental demands by making decisions in the process of making a product, or delivering a service. Because they are encouraged to self-regulate their behavior, they can make decisions to allocate resources efficiently to deal with the total variation in work conditions (Cummings 1978). To do this effectively, team members need to be given the opportunities for training to maintain and enhance their job skills.

Self-managing work teams are also said to be operating in a culture that supports employee involvement (Manz 1991). In other words team members have the power to make decisions about work processes and outcomes, in addition to having information on quality outcomes, business performance, external competition, and organization changes. SuperLeader behaviors would tend to encourage this. In addition, it is also important they have the resources to accomplish their work, and training that enables work team members to develop the knowledge required for effective performance. All this requires an environment where open communication is encouraged as well as a culture of mutual support and recognition for a job well done. The following hypothesis is therefore proposed:

Hypothesis 2: Groups with SuperLeader behaviors will have higher perceived levels of team training, team communication, team effectiveness, and support.

\section{METHOD}

\section{Sample}

Data were collected on site over a period of three days from employees working in a non-union paper mill located in a small rural community in the Northwest. The plant was a new facility and had been operating with autonomous work teams since its inception. This survey was carried out a year later and was completed by 141 employees for a 99 per cent response rate. The high level of returns was due to the fact that employees filled out the survey before the start of their respective shift. Also, the plant manager encouraged the employees to complete the surveys. Of those who completed the survey 86 percent were male and 14 percent female.

\section{Measures}

- $\quad$ Self-leadership: Self-leadership scores were obtained using the Self-Management Leadership Questionnaire developed by Manz \& Sims (1987). The 22-item questionnaire is designed to test the extent to which leaders of autonomous work groups display typical

- $\quad$ Supervision: A slightly modified version of DeCotiis and Koy's (1981) scales were used to measure various perceptions of the leader, including trust, recognition, fairness, and innovation Items were rated on a 7 point scale.

- $\quad$ Support: A subset of House and Wells' 13 item scale was used to measure supervisor support. Items were rated on a 7 point scale.

- $\quad$ Growth: Growth was measured with a single 7 point item taken from the Job Diagnostic Survey (Hackman and Oldham,) 1980

- $\quad$ Team Functions: Perceptions of team functions were assessed with scales developed by the Center for Effective Organizations. The scales measured team training, team communication, and team effectiveness. Items were rated on a 7 point scale

\section{RESULTS}

For the purpose of analysis, groups falling under the SuperLeader style of management were generated as follows: (1) a standard mean score and a standard deviation were calculated for all groups based on the sum of the scores from the Self-leadership portion of the questionnaire, and (2) groups that showed mean scores one standard deviation above the population mean were deemed to be SuperLed groups and those groups whose mean fell one standard deviation below the population mean were termed traditionally led groups. Those groups whose mean fell within one standard deviation of the population mean were deemed to be moderately participative. 
A Manova was conducted on the dependent variables of fairness, recognition, innovation, trust, growth, supervisor support, team communications, team training, and team effectiveness. The independent variable in this analysis was the degree of SuperLeader behaviors displayed in the teams, i.e., High, Medium, and Low. The combined analysis indicated that Superleader behaviors displayed a significant influence on the variables. Post hoc tests of the effects showed that all the dependent variables appeared to be strongly associated with SuperLeader behaviors. A look at the means between High, Middle, and Low SuperLeader groups indicate a linear relationship, with fairness, innovation, recognition, trust, growth, support, team communication, effectiveness, and training decreasing as SuperLeader behaviors diminished.

Table 1: Means

Fairness, Innovation, Recognition, Trust, Growth, Support, Team Communication, Training, And Effectiveness By Superleader Behavior Levels

\begin{tabular}{lccc} 
Variable & Low & Medium & High \\
\hline Fairness & & & \\
Innovation & 4.7 & 5.7 & 6.5 \\
Recognition & 6.4 & 5.6 & 6.4 \\
Trust & 4.3 & 5.4 & 6.5 \\
Growth & 4.9 & 6.0 & 6.6 \\
Support & 5.0 & 5.7 & 5.9 \\
T. Communication & 4.5 & 5.5 & 5.9 \\
T. Effectiveness & 4.5 & 5.4 & 6.2 \\
T. Training & 4.7 & 5.4 & 6.2 \\
& 4.6 & 5.3 & 4.6
\end{tabular}

Table 2: Manova

Fairness, Recognition, Innovation, Trust, Growth, Support, Team Communication, Effectiveness, And Training By Superleader Behavior Levels

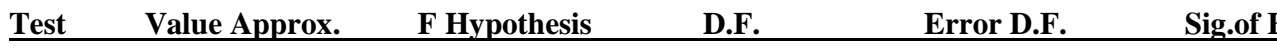

\begin{tabular}{|c|c|c|c|c|c|}
\hline Pillais & .52 & 4.9 & 18.0 & 248.0 & $.00 *$ \\
\hline Hotellings & .97 & 6.5 & 18.0 & 244.0 & $.00 *$ \\
\hline Wilks & .49 & 5.7 & 18.0 & 246.0 & $.00 *$ \\
\hline Roys & .48 & & & & \\
\hline
\end{tabular}

\begin{tabular}{lcccc} 
Variable & $\begin{array}{c}\text { Hypoth } \\
\text { SS }\end{array}$ & $\begin{array}{c}\text { Error } \\
\text { MS }\end{array}$ & F & Sig of F \\
\hline & & & & \\
Fairness & 54.4 & 1.01 & 26.9 & $.00^{*}$ \\
Recog. & 62.2 & 1.10 & 28.1 & $.00^{*}$ \\
Innov. & 72.2 & .75 & 47.9 & $.00^{*}$ \\
Trust & 55.2 & .94 & 29.1 & $.00^{*}$ \\
Growth & 16.8 & 1.1 & 7.1 & $.00^{*}$ \\
Support & 39.8 & 1.37 & 14.5 & $.00^{*}$ \\
T.Comm. & 44.5 & .93 & 23.9 & $.00^{*}$ \\
T.Effect. & 32.6 & .56 & 28.9 & $.00^{*}$ \\
T.Train. & 30.6 & 1.05 & 14.5 & $.00^{*}$ \\
& & & &
\end{tabular}




\section{DISCUSSION}

The quality of its leadership is an important factor in the success of self-managed work teams (Manz \& Sims, 2001). The results of this indicate a SuperLeader style of management seems to directly affect team member perceptions about certain supervisor behaviors, as well as their evaluation of team functioning and satisfaction with their own personal growth. Supervisors or team leaders who encourage self-leadership behaviors directly influence perceptions of trust, fairness, innovation, and growth. Team members in groups with supervisors who exhibited SuperLeader behaviors also experienced higher levels of support, communication, and training. They also rated the effectiveness of their teams as being higher than those in groups that had supervisors who did not exhibit SuperLeader behaviors. This study also supports the results found by Beekun (1989), who found in a Meta analysis that selfmanaging work teams without supervisors performed better than those with supervisors. Transferring ownership of work to those who perform the work, the leader provides the information and support, whilst the team members take ownership and autonomy for resolving work problems and implementing work related solutions. This enhances the perceptions of trust and fairness team members experience in their job, as well as the amount of influence and growth they experience in performing the duties associated with their job.

It is clear, that research studies indicate that the external leaders can contribute to the success or failure of a team (Glassop, 2002; Cohen, Chang \& Ledford 1997; Hackman, 1986; Kirkman \&Rosen, 1999). However, a unique and different leadership style is required in a self- managed team; in contrast to traditional leaders who lead by monitoring and managing, supervisors or team leaders should delegate this function back to the teams (Druskat \& Wheeler, 2003).In engaging in boundary spanning activities and developing relationships with constituents external to the team, supervisors or team leaders provide information that facilitates the team achieving its goals as well as helps developing trust and confidence of team members (Druskat \& Wheeler, 2003).

\section{REFERENCES}

1. Beekum, R. I., 1989, Assessing the effectiveness of socio-technical interventions: Anecdote or fact? Human Relations, 47(10), pp. 877-897.

2. Cohen, S. and Ledford, G. E., Jr. 1994, The effectiveness of self-managed teams: quasi-experiment, Human Relations, 47, 1.

3. Cohen, S. G. and Bailey, D. E. 1997, What makes teams work: Group effectiveness from the shop floor to the executive suite, Journal of Management, 23(3) 239-260.

4. Cohen, S. G., Chang, L., and Ledford, G. E., Jr. 1997, A hierarchical construct of self-management leadership and its relationship to quality of work life and perceived work group effectiveness, Personnel Psychology, 50: 275-308.

5. Cummings, T. G., 1978, Self- regulating work groups: A socio-technical synthesis, Academy of Management Review 11(3) pp. 625-634.

6. Druskat, V. U. and Wheller, J. V., 2003, Managing from the boundary: The effective leadership of selfmanaging work teams, Academy of Management Journal, 46, (4) pp. 435-457.

7. Dunphy, D. and Bryant, B. 1996, Teams: Panaceas or prescriptions for improved performance? Human Relations, 49, 667-699.

8. Elloy, D. 1997, The relationship between superleader behaviors and situational and job characteristics variables: An exploratory study, Journal of Business and Management, 5, (1) pp. 52-65.

9. Elloy, D. and Randolph, A. 1997, The effect of superleader behavior on autonomous work groups in a government railway service, Public Pesonnel Management, 26, (2) pp. 257-272.

10. Elloy, D., 2005, The influence of superleader behaviors on organization commitment, job satisfaction And organization self-esteem in a self-managed work team, The Leadership and Organization Development Journal, 26, 2, pp. 120-127.

11. Emery, F. E. and Trist, E. L., 1969, Socio-Technical Systems, in F.E. Emery (ed.), Systems Thinking, London: Penguin Books, pp. 281-296.

12. Glassop, L. I. 2002, The organizational benefits of teams, Human Relations, 55, pp 225-240.

13. Guzzo, R. A. and Dickson, M. W. 1996. Teams in organizations: Recent research on performance and effectiveness, Annual Review of Psychology, 47, 307-338. 
14. Hackman, J. R. and Oldham, G. R., 1975, Development of the Job Diagnostic survey, Journal of Applied Psychology, 56 (51), 388-396.

15. Hackman, J. R., 1986, The psychology of self-management in organizations, in M.S. Pollack and R.O. Pasloll (eds.) Psychology and Work: Productivity, Change and Employment, Washington, D.C.: American Psychological Association, pp. 85-165.

16. Kanungo, R. N. 1982, Measurement of job and work involvement. Journal of Applied Psychology, 67, Pp.341-49.

17. Kirkman, B. L., and Rosen, B. 1999, Beyond self-management: Antecedents and consequences of team empowerment. Academy of Management Journal, 42: 58-74.

18. Langfred C. W., 2000, The paradox of self-management: individual and group autonomy in work groups, Journal of Organizational Behavior, 21,563-588.

19. Lawler, E., Mohrman, S. A., and Ledford, G. E, Jr. 1994, Employee involvement and total quality management: Practices and results in Fortune 1000 companies, San Francisco: Jossey Bass.

20. Manz, C. E., 1986, Self Leadership: Toward an Expanded Theory of Self Influence Processes in Organizations, Academy of Management Review, 11, pp. 585-600.

21. Manz, C. and Sims, H., 1986, Leading Self-Managed Groups: A Conceptual Analysis of a Paradox, Economic and Industrial Democracy, 7, pp. 141-165.

22. Manz, C. E. and Sims, H. P., 1987, Leading workers to lead themselves: The external leadership of selfmanaged work teams, Administrative Science Quarterly, 32, pp. 106-128.

23. Manz, C. and Sims, H., 1990, Super Leadership: Leading Others to Lead Themselves, New York: Berkely.

24. Manz, C. and Sims, H., 1991, Superleading: Beyond the myth of heroic leadership, Organizational Dynamics, Spring, pp. 18-35.

25. Manz, C. and Sims, H., 1993, Leading workers to lead themselves: The external leadership of self-managed work teams, Administrative Science Quarterly, 32, pp.106-128.

26. Manz, C. and Sims H.P., 2001, The New Superleadership, Koehler Publishers Inc.

27. Mohrman, S. A., Cohen, S. A., and Mohrman, A., 1995, Designing Team-Based Organizations, Jossey Bass.

28. Pearson, C.A.L., 1992, Autonomous work groups: An evaluation at an industrial work site, Human Relations, 45.

29. Sims, H. and Szillagyi, R., 1976, The measurement of job characteristics, Academy of Management Journal, 19(2), pp. 195-212.

30. Stewart, G. L. and Manz, C. C., 1995, Leadership of self-managed work teams: A typology and integrative model, Human Relations, 48, 7, 747-769.

31. Wall, T., Kemp, N., Jackson, P., and Clegg, C., 1986, Outcomes of Autonomous Work Groups: A Long Term Field Experiment, Academy of Management Journal, 29(2), pp. 280-304. 